\title{
CALCULATION OF FIRE RESISTANCE OF REINFORCED CONCRETE COLUMN BY THE ZONE METHOD
}

\author{
Lidija MILOŠEVIĆ ${ }^{1}$, Dušica PEŠIĆ ${ }^{2}$
}

Research article

Thistract:
that is exposed to fire from two sides. Calculation of the temperatures has been made
depending on whether the heat flow within the reinforced concrete column is one-
dimensional or two-dimensional. The temperature of concrete and the temperature of
reinforcement are calculated by the Hertz's method. The values of concrete strength and
reinforcement, as well as the width of the damage zone of concrete during a certain period
of exposure to fire have been calculated. Resistance to the effects of fire on reinforced
concrete column has been calculated by the zone method. The time of the resistance of
column to the effects of fire has been determined according to the moment capacity of
reinforced concrete column.
Reinforced concrete column, Coefficient of reduced strength, Width of damage zone,
Load-carrying capacity.

\section{Introduction}

Modern building design regulations give significant prominence to construction fire protection. The set of standards collectively named Eurocode (EN 1992-1-1, 2004; EN 1992-1-2, 2004; EN 1992-2, 2005; EN 1992-3, 2006) is a European code package for building design.

Analysis of a building's fire resistance is a complex process, as it involves multiple variables such as fire development and duration (ISO, 1975), temperature distribution inside the construction elements, changes in building material properties, or interaction between construction elements and the building load impact (Milošević and Milutinović, 2009; Tomanović, 2005). The process commonly involves three different components:

- Fire hazard analysis and designation of fire impact on surrounding building elements;

- Thermal analysis for temperature calculation over time in each building element;

- Structural analysis, in order to determine the tension and strength of each construction element and the probability of local or progressive building collapse during fire.

The reinforced concrete column for which we calculated fire resistance (Fig. 1) has the following properties:

- height $4000 \mathrm{~mm}$,

- cross section 500x300 mm,

- thickness of protective concrete layer $30 \mathrm{~mm}$,
- number of reinforcements is 6, diameter ø20,

- characteristic compressive strength of concrete $f_{c c}=50 / 60 \mathrm{MPa}$,

- characteristic strength of steel reinforcement $f_{a c}=500 \mathrm{MPa}$.

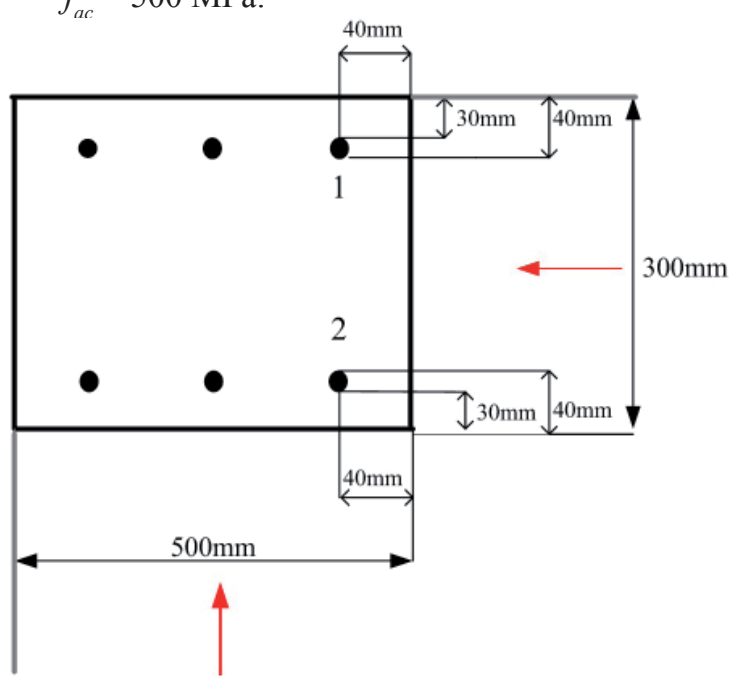

Fig. 1 Reinforced concrete column dimensions

We calculated the following properties of the reinforced concrete column during fire (Zha, 2003):

- cross-section concrete temperature,

- reinforcement temperature,

- reinforcement strength reduction factor,

- concrete strength reduction factor,

- width of damaged concrete zone,

\footnotetext{
University of Niš, Faculty of Occupational Safety, Serbia, lidija.milosevic@znrfak.ni.ac.rs

2 University of Niš, Faculty of Occupational Safety, Serbia
} 
- load-carrying capacity of the reinforced concrete column,

- equivalent fire duration for given reinforced concrete column.

\section{Materials and methods}

\section{Temperatures Inside the Reinforced Concrete Column (Hertz's method)}

With a one-dimensional heat flow, temperature as a function of time $\Delta t(x, \tau)$ is expressed as follows (Hertz, 1981a):

$$
\Delta t(x, \tau)=f_{1}(x, \tau)+f_{2}(x, \tau)+f_{3}(x, \tau)
$$

where $f_{1}(x, \tau), f_{2}(x, \tau)$, and $f_{3}(x, \tau)$ are functions for solving the heat conduction equation for specific boundary conditions. The functions are expressed as follows:

$$
\begin{aligned}
& f_{1}(x, \tau)=E\left(1-\frac{x}{3,363 \sqrt{a \tau}}\right)^{2} \\
& f_{2}(x, \tau)=D e^{-x u} \sin \left(\frac{\pi \tau}{C}-x u\right) \text { for } \mathrm{u}=\sqrt{\frac{\pi}{2 a c}} \\
& f_{3}(x, \tau)=\frac{D+E}{2\left(e^{L C}-1\right)}\left(1-e^{\left(L(\tau-C)-x \sqrt{\frac{L}{a}}\right)}\right)
\end{aligned}
$$

where:

$D, C, E$ parameters whose values are given in Tab. 1 and which depend on the heating mode,

$L \quad$ parameter which depends on the cooling flow is calculated according to the expression.

For standard fire exposure, $f_{3}$ is always zero and it should not be included in the calculation.

Tab. 1 Parameters values

\begin{tabular}{|c|c|c|c|}
\hline Time [h] & $\mathbf{C}[\mathbf{h}]$ & $\mathbf{D}\left[{ }^{\circ} \mathbf{C}\right]$ & $\mathbf{E}\left[{ }^{\circ} \mathbf{C}\right]$ \\
\hline 0,5 & 1,0 & 150 & 600 \\
\hline 1,0 & 2,0 & 220 & 600 \\
\hline 1,5 & 3,0 & 310 & 600 \\
\hline 2,0 & 4,0 & 360 & 600 \\
\hline 3,0 & 6,0 & 410 & 600 \\
\hline 4,0 & 8,0 & 460 & 600 \\
\hline
\end{tabular}

For a two-dimensional heat flow, Hertz's method (Hertz, 1981a; Hertz, 1981b) has to be modified as regards temperature change along the $x$ and $y$ axes $\Delta t(x, y, \tau)$; hence, it can be expressed as:

$$
\Delta t(x, y, \tau)=\Delta t_{0}\left(\xi_{\tau, x}+\xi_{\tau, y}-\xi_{\tau, x} \xi_{\tau, y}\right)
$$

where:

$\Delta t_{0}$ temperature increment on the construction element surface for the time $\tau$,

$\xi_{\tau, x}$ dimensionless temperature increment parameter on the $x$-axis,

$\xi \tau, y$ dimensionless temperature increment parameter on the $y$-axis,

$y \quad$ distance on the $y$-axis, $[\mathrm{m}]$.

\section{Calculated temperature values inside the reinforced concrete column}

When calculating temperatures inside the reinforced concrete column, we assumed that the column is exposed to fire on two sides.

The reinforced concrete column is divided into zones. We calculated the temperatures in zone sections at the distances of $x=30 \mathrm{~mm}, x=90 \mathrm{~mm}$, and $x=150 \mathrm{~mm}$. Temperatures calculated by Hertz's method for the period of $0.5 \div 4 \mathrm{~h}$ are given in Fig. 2 .

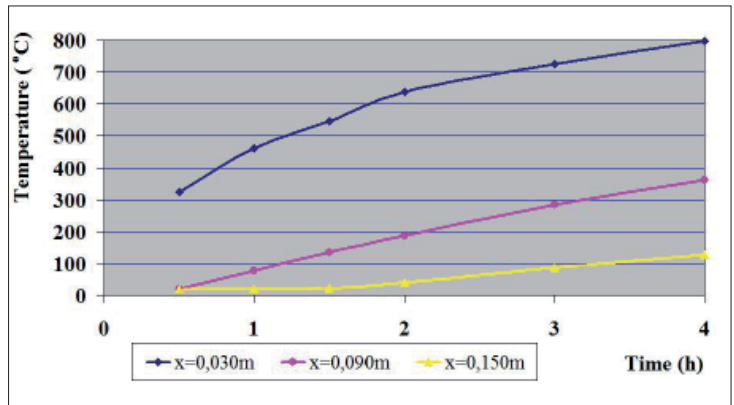

Fig. 2 Temperatures inside the column at $x$-axis distances

Temperatures calculated by Hertz's method for armatures 1 and 2 are given in Fig. 3 .

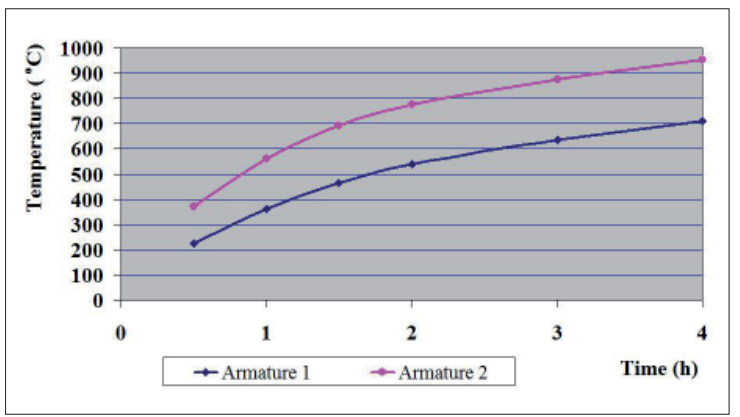

Fig. 3 Temperatures of column reinforcements 


\section{Results}

\section{Fire Resistance of the Reinforced Concrete Column}

The area of the reinforced concrete column cross section, $A_{c}$, is:

$$
A_{c}=500 \cdot 300=150000 \mathrm{~mm}^{2}
$$

The steel reinforcement area $A_{a}$ is:

$$
A_{a}=6(20 / 2)^{2} \cdot 3,14=1885 \mathrm{~mm}^{2}
$$

The load-carrying capacity of the reinforced concrete column under normal conditions $N_{n}$ is calculated as follows:

$$
\begin{gathered}
N_{n}=A_{c} \frac{\alpha_{c} f_{c c}}{\gamma_{c}}+A_{a} \frac{f_{a c}}{\gamma_{a}} \\
N_{n}=150000 \frac{0,85 \cdot 50}{1,5}+1885 \frac{500}{1,15}= \\
=5069565,22 \mathrm{~N}=5,07 \mathrm{MN}
\end{gathered}
$$

where:

$\alpha_{c} \quad$ load duration factor,

$\gamma_{c}$ partial safety coefficient of concrete for load-carrying boundary conditions,

$\gamma_{a}$ partial safety coefficient of steel reinforcement for load-carrying boundary conditions.

The load-carrying capacity of the reinforced concrete column during fire is calculated as follows:

$$
N_{\mathrm{r}, \mathrm{fi}}=\eta_{f i} N_{\mathrm{n}}=0,7 \cdot 5,07=3,549 \mathrm{kN}
$$

where:

$\eta_{f i} \quad$ load level during fire.

\section{The Zone Method}

The zone method for calculating fire resistance of construction elements focuses on the impact of fire heat on concrete inside the sections (zones), whereby temperature is determined as its mean value in the centre of each section (EN 1992-1-2, 2004).

Strength reduction factor $\mathrm{kc}(\mathrm{t})$ of silica aggregate concrete is calculated with the following expressions:

$$
\begin{array}{lc}
\text { For } 20{ }^{\circ} \mathrm{C} \leq t \leq 100{ }^{\circ} \mathrm{C} & k_{\mathrm{c}}(t)=1,0 \\
\text { For } 100{ }^{\circ} \mathrm{C} \leq t \leq 200{ }^{\circ} \mathrm{C} & k_{\mathrm{c}}(t)=\frac{105-0,05 t}{100} \\
\text { For } 200^{\circ} \mathrm{C} \leq t \leq 400^{\circ} \mathrm{C} & k_{\mathrm{c}}(t)=\frac{230-0,2 t}{200} \\
\text { For } 400{ }^{\circ} \mathrm{C} \leq t \leq 800^{\circ} \mathrm{C} & k_{\mathrm{c}}(t)=\frac{540-0,6 t}{400}
\end{array}
$$

For $800{ }^{\circ} \mathrm{C} \leq t \leq 900{ }^{\circ} \mathrm{C} \quad k_{\mathrm{c}}(t)=\frac{71-0,07 t}{100}$

For $900{ }^{\circ} \mathrm{C} \leq t \leq 1000{ }^{\circ} \mathrm{C} \quad k_{\mathrm{c}}(t)=\frac{44-0,04 t}{100}$

For $1000{ }^{\circ} \mathrm{C} \leq t \leq 1100{ }^{\circ} \mathrm{C} \quad k_{\mathrm{c}}(t)=\frac{34-0,03 t}{100}$

For $1100{ }^{\circ} \mathrm{C} \leq t \leq 1200{ }^{\circ} \mathrm{C} \quad k_{\mathrm{c}}(t)=\frac{120-0,1 t}{100}$

The mean value of the strength reduction factor $k_{c, m}$ is determined based on the expression:

$$
k_{c, m}=\frac{1-\frac{0,2}{n}}{n} \sum_{i=1}^{n} k_{\mathrm{c}}\left(t_{i}\right)
$$

Effective width of a section damaged by tensile stress is determined based on the damaged section width $a_{z}$, which, in turn, is calculated with the following expression:

$$
a_{z}=\omega\left[1-\left(\frac{k_{c, m}}{k_{c}\left(t_{M}\right)}\right)^{1,3}\right]
$$

where:

$\omega$ half width of section

$k_{c}\left(t_{M}\right)$ strength reduction factor of concrete at temperature $t$ in the center of slice.

\section{Calculated fire resistance values for the reinforced concrete column}

We divided the cross section of the reinforced concrete column into zones and calculated temperatures in the sections of those zones over the distances $x=30 \mathrm{~mm}, x=90 \mathrm{~mm}$, and $x=150 \mathrm{~mm}$. Concrete strength reduction factor in the column's cross section is given in Fig. 4.

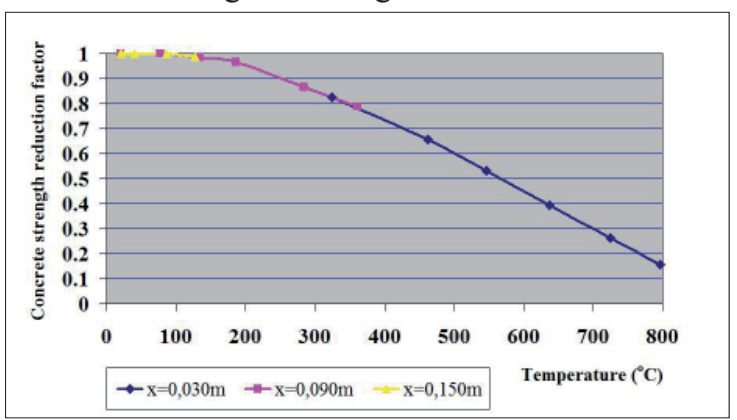

Fig. 4 Change in concrete strength reduction factor with temperature

Reinforcement 1 is exposed to fire on one side, whereas reinforcement 2 is exposed to it on two sides. Fig. 5 shows temperature values for 
a one-dimensional heat flow for reinforcement 1 and a two-dimensional heat flow for reinforcement 2, all by Hertz's method (Hertz, 1981a; Hertz, 1981b).

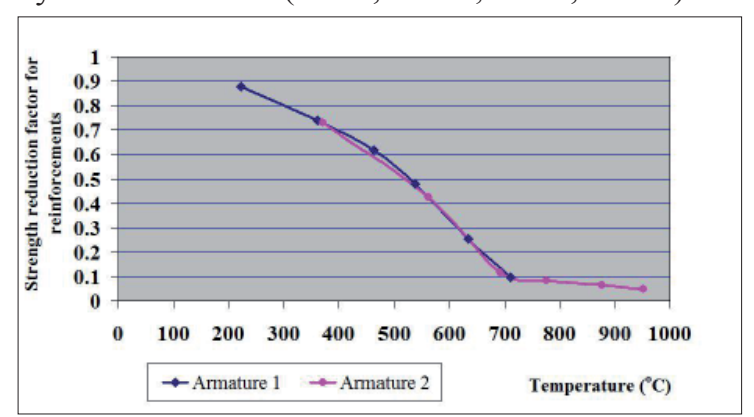

Fig. 5 Change in strength reduction factor for reinforcements 1 and 2 in the reinforced concrete column during fire

Fig. 6 shows the width values of the damaged concrete zone and Fig. 7 shows the load-carrying capacity values for the reinforced concrete column during fire, all calculated by the zone method.

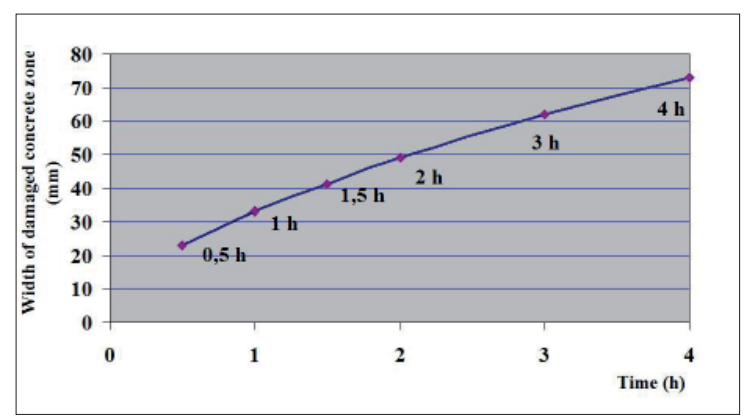

Fig. 6 Width of damaged concrete zone

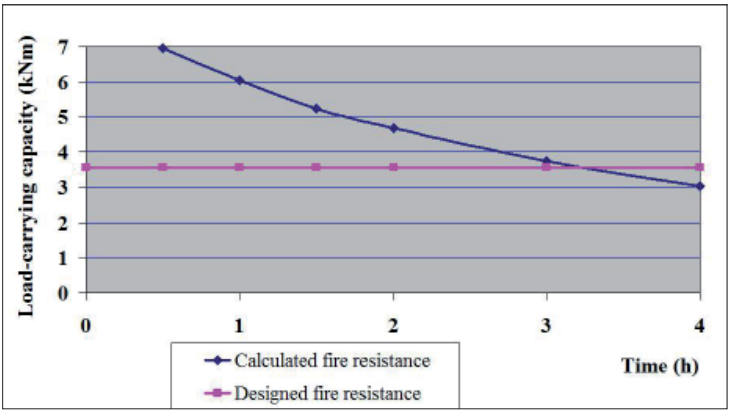

Fig. 7 Change in load-carrying capacity of the reinforced concrete column during fire

As shown in Figure 7, the reinforced concrete column is resistant to fire for more than 3 hours.

\section{Equivalent Fire Duration of the Reinforced Concrete Column}

During calculation, we used a dimensionless parameter, degree of room openness, as a general criterion for determining the character of mass exchange of gaseous fractions and the fire point of origin. Degree of openness is expressed as follows:

$$
\bar{O}=\frac{A_{o} h_{o}^{0,5}}{V^{0,666}}
$$

where:

$A_{o}$ area of openness,

$h_{o}$ depth of openness,

$V$ volume of room.

As seen in Fig. 8, an increase in the dimensionless parameter - degree of room openness - causes an increase in the equivalent fire duration, which means that constructions maintain their stability longer during fire. When the duration of free fire development decreases, so does its equivalent duration.

Duration of free fire development can be regulated through changing the quantity of present mass fire load or through constructive solutions and active protection, such as extinguishment. Simultaneously, adequate preventive and tactical measures which directly affect the equivalent fire duration have to be used.

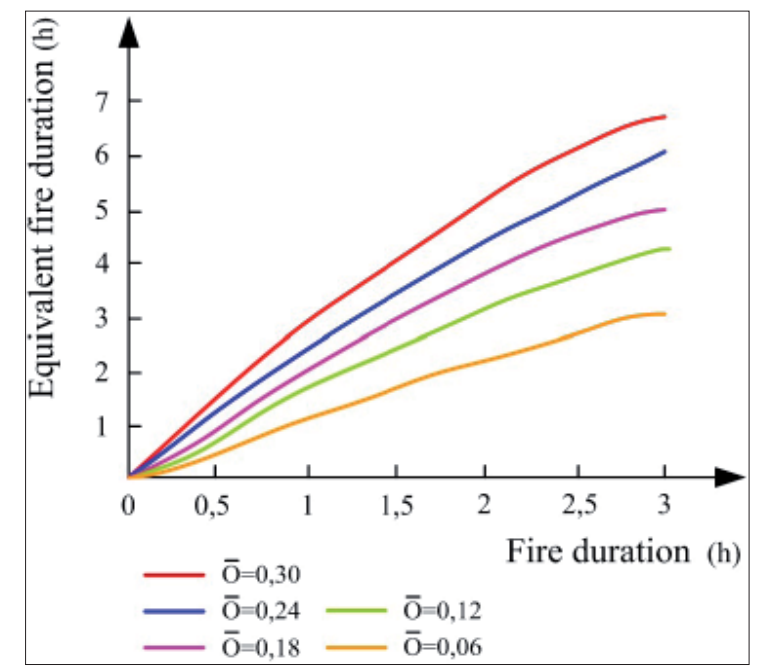

Fig. 8 Equivalent fire duration for reinforced concrete columns

\section{Conclusion}

Analysis of reinforced concrete column fire resistance involves a set of procedures for thermal and mechanical analyses. Based on obtained results from thermal and mechanical analyses and proper input data on construction properties, it is possible to calculate the reduction of the construction's load-carrying capacity during analysis of its fire resistance. 
Standard fire duration will be equivalent to the duration of an actual fire if the impacts of standard and actual fires on a given construction are the same. The quantity that expresses the congruence between standard and actual fire is the equivalent fire duration.

\section{References}

EN 1992-1-1:2004. Design of concrete structures. General rules and rules for buildings.

EN 1992-1-2:2004. Design of concrete structures. General rules. Structural fire design.

EN 1992-2:2005 Design of concrete structures. Concrete bridges. Design and detailing rules.

EN 1992-3:2006 Design of concrete structures. Liquid retaining and containing structures.

HERTZ, K. (1981a). Stress Distribution Factors, Report No. 158 (reissued as $2^{\text {nd }}$ edn Report 190, 1988), Institute of Building Design, Technical University of Denmark.

HERTZ, K. (1981b). Simple Temperature Calculations of Fire Exposed Concrete Constructions, Report No. 159, Institute of Building Design, Technical University of Denmark.

ISO 834:1975. Fire Resistance Tests - Elements of Building Construction.

MILOŠEVIĆ, L., MILUTINOVIĆ, S. (2009). Thermal properties of Concrete Construction During Fire. In Požární ochrana 2009 - Sborník přednášek - XVIII ročníku mezinárodní konference, Ostrava, Česká republika, 2009, pp. 360-371.

TOMANOVIĆ, D. (2005). Integralni metod modelovanja temperaturskog režima požara u prostoriji, Fakultet zaštite na radu, Niš, 2005.

ZHA, X.X. (2003). Three-dimensional non-linear analysis of reinforced concrete members in fire, Buildings and Environment, 2003, 38, pp. 297-307. 